\title{
Climate change, 24-hour movement behaviors, and health: a mini umbrella review
}

\author{
Evaline Zisis ${ }^{1}$, Shawn Hakimi ${ }^{1}$ and Eun-Young Lee ${ }^{1,2^{*}}$ (D)
}

\begin{abstract}
Background: The worsening climate change and alarming prevalence of communicable and non-communicable diseases continue to threat human life and existence. Accumulating evidence suggests that favorable patterns of 24-h movement behaviors, high physical activity, low sedentary behavior, and adequate sleep, may positively contribute to achieving dual benefits of climate change mitigation and disease prevention. The purposes of this mini umbrella review were to summarize the most up-to-date, high-level evidence exploring the relationships between climate change, 24-h movement behaviors, and health and elaborate on the mechanisms linking the three variables of interest.
\end{abstract}

Methods: A systematic search of electronic databases was performed in PubMed and Google Scholar during March-October 2020. Inclusion criteria were: (1) systematic review; (2) reviewed relationships between climate change and movement behaviors and/or health in any directions; (3) written in English; (4) published in 2010-2020. Narrative synthesis was conducted to highlight the main relationships observed and address the current state of knowledge and priorities for future research. In order to illustrate the potential mechanisms between climate change, movement behaviors, and health, the main results from included systematic reviews were summarized and a conceptual framework was developed for future research.

Results: Based on the evidence from eight systematic reviews published in the past decade, multi-directional (i.e., uni-, bi-, or U-shaped) links were observed between climate change and varying human health outcomes. However, little is understood about the association between climate change and 24-h movement behaviors. Two reviews suggested the negative impact of climate change on sleep and bi-directional relationships between climate change and physical activity/sport. One review included two studies suggesting the unfavorable impact of climate change on sedentary behavior; however, the evidence was limited. Finally, no reviews examined the mechanisms by which climate change, movement behaviors, and health impact one another. Based on the findings of this mini umbrella review, a conceptual framework is proposed that could guide future work to unpack mechanisms between climate change, movement behaviors, and health.

Conclusions: This mini umbrella review highlights the importance of better understanding the mechanisms between climate change, movement behaviors, and health in developing effective mitigation and adaptation strategies to climate change, while paying close attention to vulnerable countries/communities/population groups.

Keywords: Population health, Chronic disease, Global warming, Natural disaster, Physical activity

\footnotetext{
* Correspondence: eunyoung.lee@queensu.ca

'School of Kinesiology and Health Studies, Queen's University, KHS 307, 28

Division St, Kingston, ON KZL3N6, Canada

2Department of Gender Studies, Queen's University, Kingston, ON, Canada
}

(c) The Author(s). 2021 Open Access This article is licensed under a Creative Commons Attribution 4.0 International License, which permits use, sharing, adaptation, distribution and reproduction in any medium or format, as long as you give appropriate credit to the original author(s) and the source, provide a link to the Creative Commons licence, and indicate if changes were made. The images or other third party material in this article are included in the article's Creative Commons licence, unless indicated otherwise in a credit line to the material. If material is not included in the article's Creative Commons licence and your intended use is not permitted by statutory regulation or exceeds the permitted use, you will need to obtain permission directly from the copyright holder. To view a copy of this licence, visit http://creativecommons.org/licenses/by/4.0/. 


\section{Background}

Since the Industrial Revolution, economic activities have relied on the burning of fossil fuels, which has led to an increase in atmospheric carbon dioxide concentrations and other greenhouse gas (GHG) emissions [1]. As a result, an increased greenhouse effect has led to warming of the earth's atmosphere. Climate change poses a great threat to several aspects of human life including sustainability [2], economy [3], and health [4]. For example, yearly deaths attributable to climate change are expected to surpass 250,000 between the years 2030 and 2050 [5]. Climate change may also impact human health indirectly by affecting the availability of resources necessary for human life such as local food, safe outdoor environments, or health-related behaviors such as active commuting [6, 7]. Given this startling evidence, minimizing negative impacts of climate change on human health has been a focus of public health [8].

In addition to the threat from climate change to human health, lack of physical activity (PA), sedentariness, and inadequate sleep have been associated with varying health outcomes [9-11]. PA, sedentary behavior (SB), and sleep are three main movement behaviors that occur in a 24-h period, known as 24-h movement behaviors [12]. In general, global populations, particularly those living in rapidly developing and developed countries, have shown low levels of PA (also known as physical inactivity), increased reliance on motorized vehicles, and electronic screen-based home entertainment, and fewer physically demanding professions [13]. These behavioral changes as a result of industrialization and urbanization, along with improved technology and resources have contributed in reducing the physical demands of day-today life $[14,15]$. Together, all these developments and subsequent lifestyle changes likely led to increased energy consumption and GHG emissions, and have ultimately exacerbated climate change [16].

Though limited to observational studies, the recent time-use epidemiology literature emphasizes that reallocation of time between PA, SB, and sleep (e.g., reallocating $30 \mathrm{~min}$ of screen time with PA) is favorably associated with weight change [17], body mass index [18], waist circumference [19], obesity [20], executive functioning [21], cardiometabolic health [22], symptoms of fatigue [23], and all-cause mortality [24] in varying age and population groups. In addition to the known health benefits of re-allocating movement behaviors (e.g., replacing 30-min of SB with $\mathrm{PA}$ ), the Intergovernmental Panel on Climate Change report highlighted that lifestyle behaviors and cultural change have great potential for climate change mitigation and adaptation efforts [25]. Given that climate change mitigation and health promotion efforts can go hand in hand, a better understanding of the associations between climate change, 24$\mathrm{h}$ movement behaviors, and health is important.

Research on climate change and human health has been gaining traction over the past few decades; however, mechanisms between climate change, 24$\mathrm{h}$ movement behaviors, and health inclusively, and the role that 24-h movement behaviors may play in moderating or mediating the relationship between climate change and health are largely unexplored. Better understanding of such complex mechanisms may inform future climate change mitigation and adaptation strategies. The purposes of this mini umbrella review were 1) to summarize the findings of systematic reviews exploring the topics of climate change and 24-h movement behaviors and/or health and 2) to elaborate on the mechanisms linking the three variables of interest (i.e., climate change, 24-h movement behaviors, and health).

\section{Methods}

This review is in a form of mini-review which summarizes "the most salient concepts related to a topic while reporting the most relevant and current findings" [26]. Furthermore, umbrella review was utilized to offer possible solutions and future directions that could address a broad scope of issues related to climate change and movement behaviors and/or health [27]. To conduct a mini umbrella review, peer-reviewed systematic reviews explaining the associations between climate change and 24-h movement behaviors and/or health outcomes published in the past 10 years were systematically examined and summarized, using Preferred Reporting Items for Systematic Reviews and Meta-Analyses (PRISMA) guidelines [28]. Only systematic reviews were considered given the vast scope of the topic and heterogeneity that exist in each variable of interest across different studies with the following definitions for each variable of interest. Climate change is operationalized as one of the biggest issues of our time due to anthropocentric activities, including shifting weather patterns, rising sea levels, greenhouse gases effect, poor air quality and air pollution, patterns and intensities of natural disasters (e.g., extreme rain falls, droughts, floods, storm, bushfires), extreme weather events, and allergens and disease vectors (e.g., ticks, bugs, blackflies, mosquitoes) [29, 30]. Based on the time-use epidemiology thinking in recent years [12, 31], 24-h movement behaviors indicate three key movement behaviors that individuals engage within a 24-h period, which includes PA, SB, and sleep. Additionally, for this review, physical, mental, and social well-being, as well as communicable diseases (CD) and non-communicable diseases (NCD), were considered as health outcomes inclusively [32]. 


\section{Literature search}

A search for systematic reviews on the topics encompassing climate change, 24-h movement behaviors and/ or health was performed (EZ) in PubMed in March 2020 using the following keywords: ("climate change" OR "global warming)" OR ("sleep" OR "PA" OR "physical inactivity" OR "sedentary behav") OR "health". The year range of 2010-2020 was set to identify only the most up-to-date systematic reviews. Google Scholar was searched using similar keywords (SH and EL) to ensure that all relevant reviews were captured. The list was cross validated with the results from PubMed. A top-up search was conducted on June 1, 2020, and expert suggestion was received on October 1, 2020.

\section{Inclusion criteria}

Review articles were deemed eligible for inclusion if the following criteria were met: 1) systematic review; 2) reviewed relationships between climate change and 24$\mathrm{h}$ movement behaviors and/or health (i.e., reviews were deemed eligible if climate change and any of the three 2h movement behaviors or health were included in their investigation); 3) in English; 4) published in 2010 and 2020 .

\section{Screening process and data extraction}

The screening criteria were established a priori (EL). Duplicates were removed and searched reviews were screened based on their titles and abstracts then full-text by two reviewers (EZ and $\mathrm{SH}$ ). Data screening was supervised by the principal investigator (EL). A data extraction form was developed by the principal investigator (EL) and the main data extractor (EZ) which included study characteristics (e.g., authors, year of publication), number of original articles included in each review, relationships observed, topic of interest, and summary of findings. Data extraction was conducted by the first author (EZ) then verified by the principal investigator (EL).

\section{Evidence synthesis}

Narrative synthesis was conducted (EZ) and verified (SH and EL) to highlight the main relationships observed and to address the current state of knowledge and priorities for future research. In order to illustrate the potential mechanisms between climate change and 24$\mathrm{h}$ movement behaviors and/or health, the main results from the included systematic reviews were summarized and a conceptual framework was developed (EL).

\section{Results}

Searches in PubMed and Google Scholar yielded 276 articles (Fig. 1). A total of six reviews met the inclusion criteria. Another review was identified through the topup-search in June 2020 and one additional review was suggested by an expert in October 2020, making up a total of eight systematic reviews included in this review. Of the eight reviews, six evaluated the relationships between climate change and health [33-38], one examined the relationship between climate change and sleep [39], and one evaluated the relationship between climate change and PA [40]. One systematic review [40] was published in the year of 2021; however, it was captured in our search in 2020, thus, included in our review. A descriptive summary and the main findings are presented in Table 1 . Systematic reviews included in this review [33-40] had a total of 457, non-mutually exclusive, independent articles and the search time frame ranged from no set time limit up to the year of 2020. None of the included reviews had a specific age group or geographical location of interest; However, one review had a specific focus on developing countries only, given their vulnerability to climate change [35]. All systematic reviews captured from our searches that meet the eligibility criteria were included in evidence synthesis regardless of its quality given the explanatory nature of the present review. In examining the associations between climate change and 24-h movement behaviors and/or health, indicators for each variable of interest used were largely heterogenous across the reviews.

\section{Climate change and health}

Of six reviews [33-38], three reviews [34, 36, 37] evaluated the effects of climate change on physical health outcomes. A bi-directional relationship between global warming and obesity was noted in one review [34], describing that global warming has a negative impact on the obesity epidemic through food supply/price and adaptive thermogenesis (i.e., reduced seasonal exposure to colder climate decreases energy expenditure and contributes to adiposity). Conversely, global warming is exacerbated due to obesity epidemic through increased energy consumption and GHG emissions [34]. Furthermore, extreme weather events caused by global warming (e.g., heat waves, wildfires, drought), led to increased morbidity and mortality [37]. Rising temperatures also increased risk for cardiovascular and respiratory dysfunctions, due to increased concentrations of air pollutants and ozone [37]. Moreover, changes in temperature and rainfall patterns caused by global warming are expected to increase the spread of infectious diseases [36, 37]. Increased temperatures due to climate change was also shown to impact occupational health whereby there is an inverse U-shaped relationship between maximum daily temperature and daily injury claims among outdoor workers [36].

Two reviews focused on the relationships between climate change-related indicators and mental health. One of these reviews [35] found that experiences with natural 


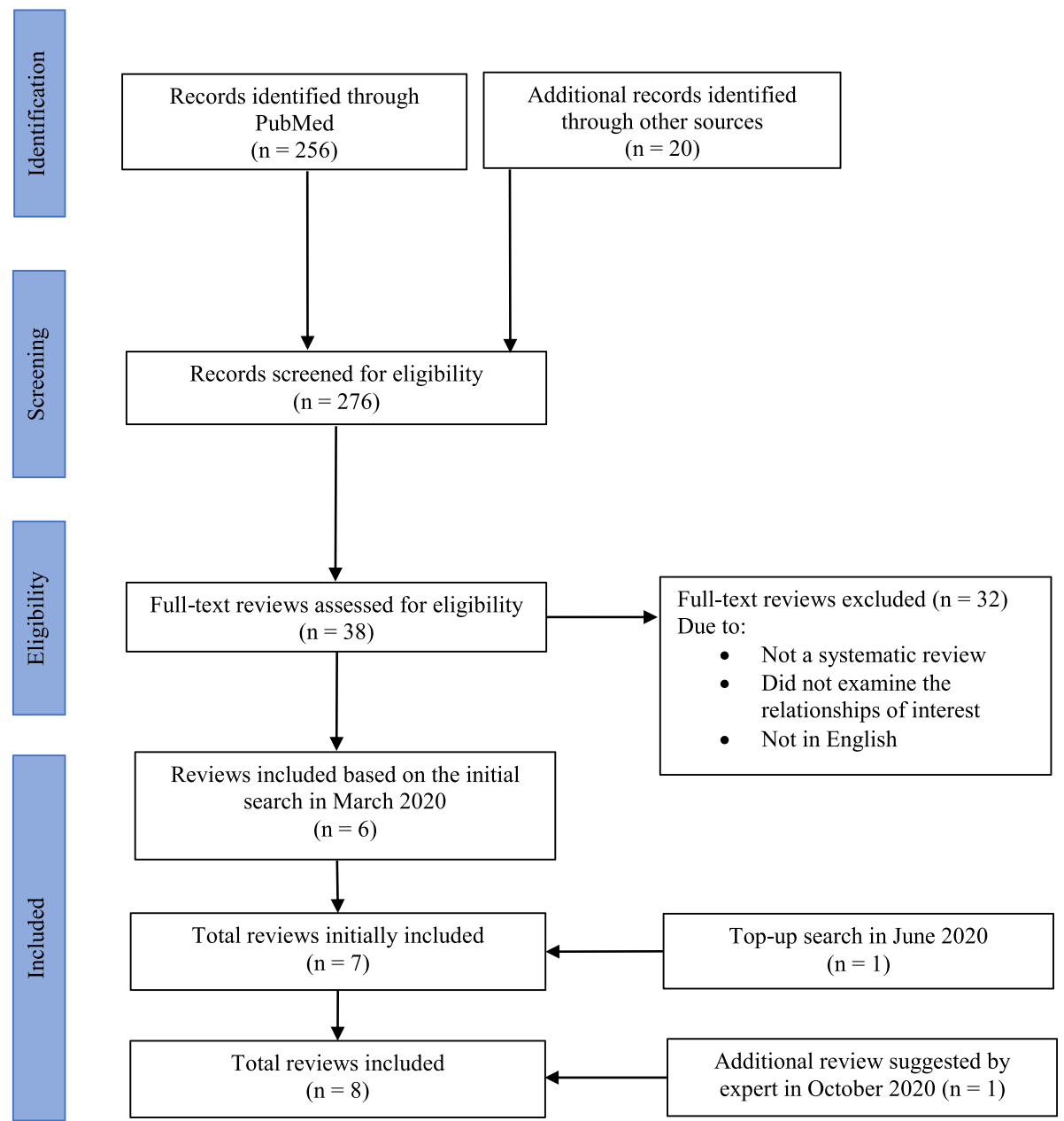

Fig. 1 PRISMA flow diagram of the literature reviewing process

disasters due to climate change are associated with increased rates of post-traumatic stress disorder, injury, depressive disorder, and anxiety disorder. In addition, the review [35] suggested that climate change-related natural disasters disproportionately affect women, individuals with older age and/or poor health status, and those who witnessed death/dead bodies. Another review [39] indicated that rising temperature and extreme weather events due to climate change are associated with impaired sleep due to fear or depression.

One review [33] prospectively examined how public health and climate change mitigation strategies produce both health and environmental benefits and risks. Results showed that increased social capital has potential health risks by increasing fear and misconceptions within social networks about climate change. The review also suggested that urban design and planning strategies as a response to climate change (e.g., expanding green spaces, walkable neighborhoods, bike paths) can have a positive influence on both public health and climate change mitigation while poor urban planning (e.g., urban heat island effect) can increase health risks.

One review [38] specifically examined the impact of climate change-related water disasters on population health. The review highlighted that people in a vulnerable situation (e.g., living in poverty or unstable dwellings, lack of access to health care) are at an increased risk for mortality and morbidity. For instance, among residents in Southeast Florida, rising sea levels were particularly dangerous for those who are low-income, lower education levels, non-English speaker, older age, visible minority, or those with disability [41].

\section{Climate change and 24-h movement behaviors}

One review evaluated the relationship between climate change and sleep [39] and another review examined the relationship between climate change and PA [40]. Rifkin and colleagues [39] investigated how changes in temperatures, extreme weather events, and natural disasters impact human sleep. Findings from their review showed 


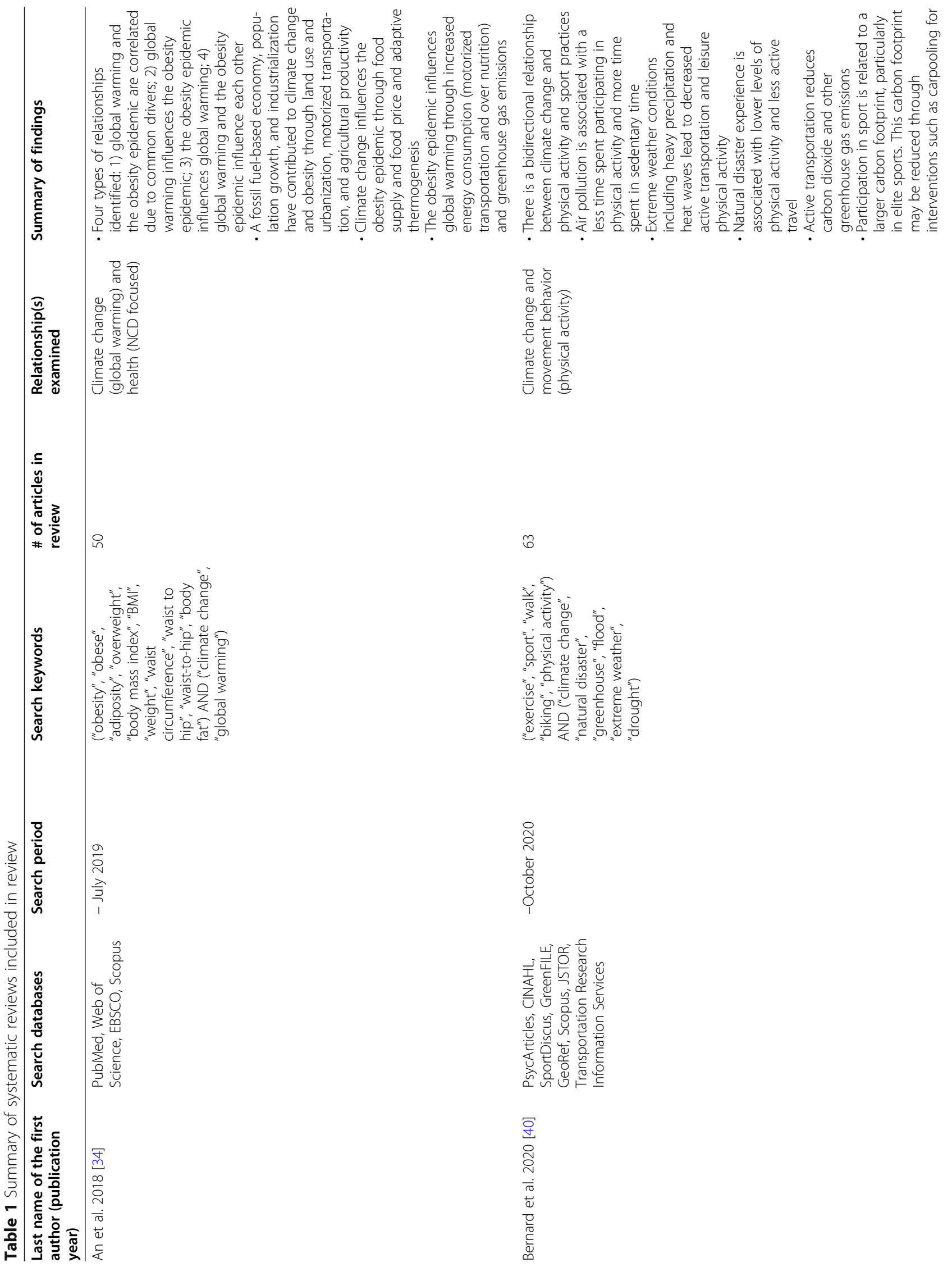




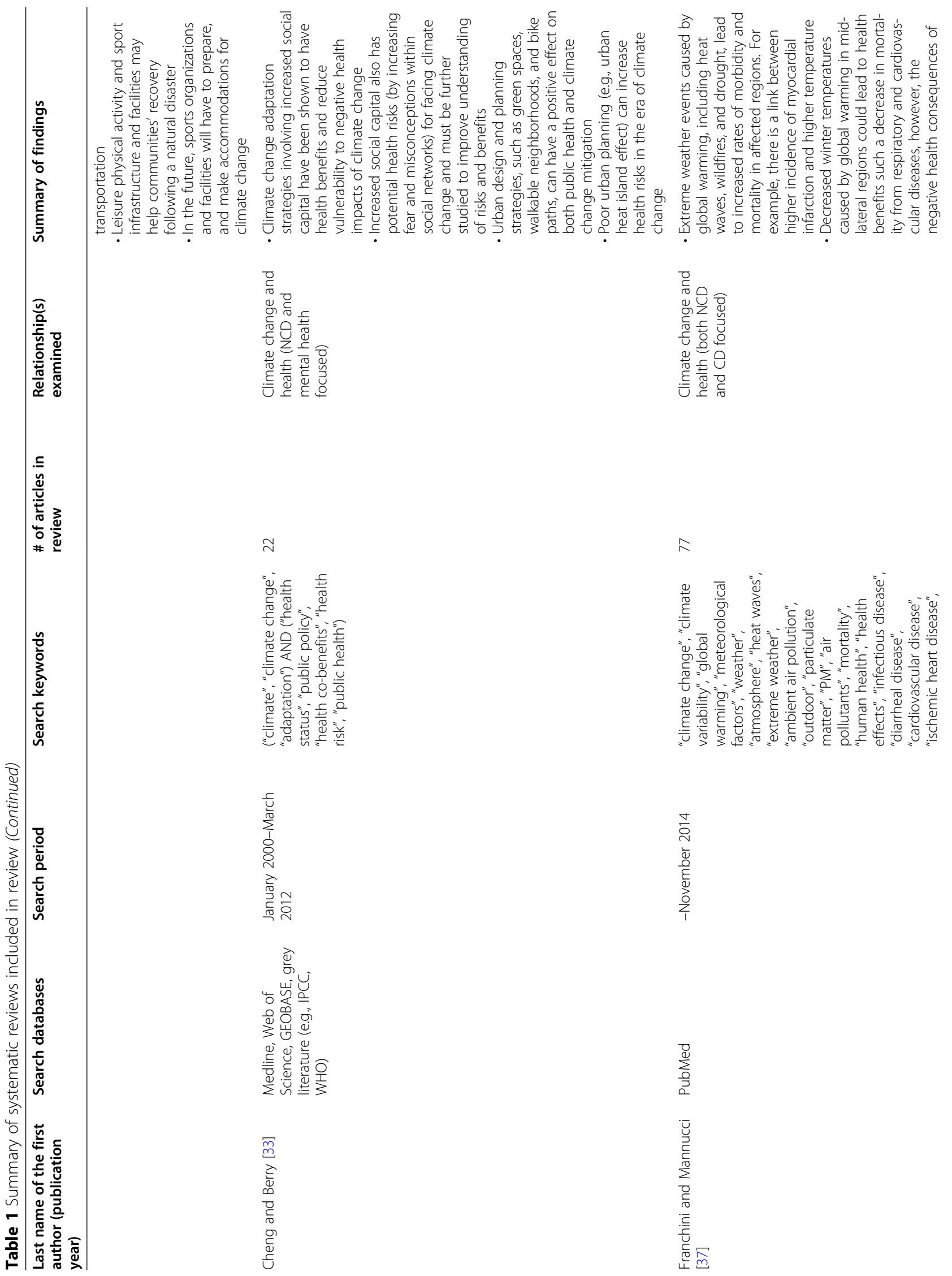




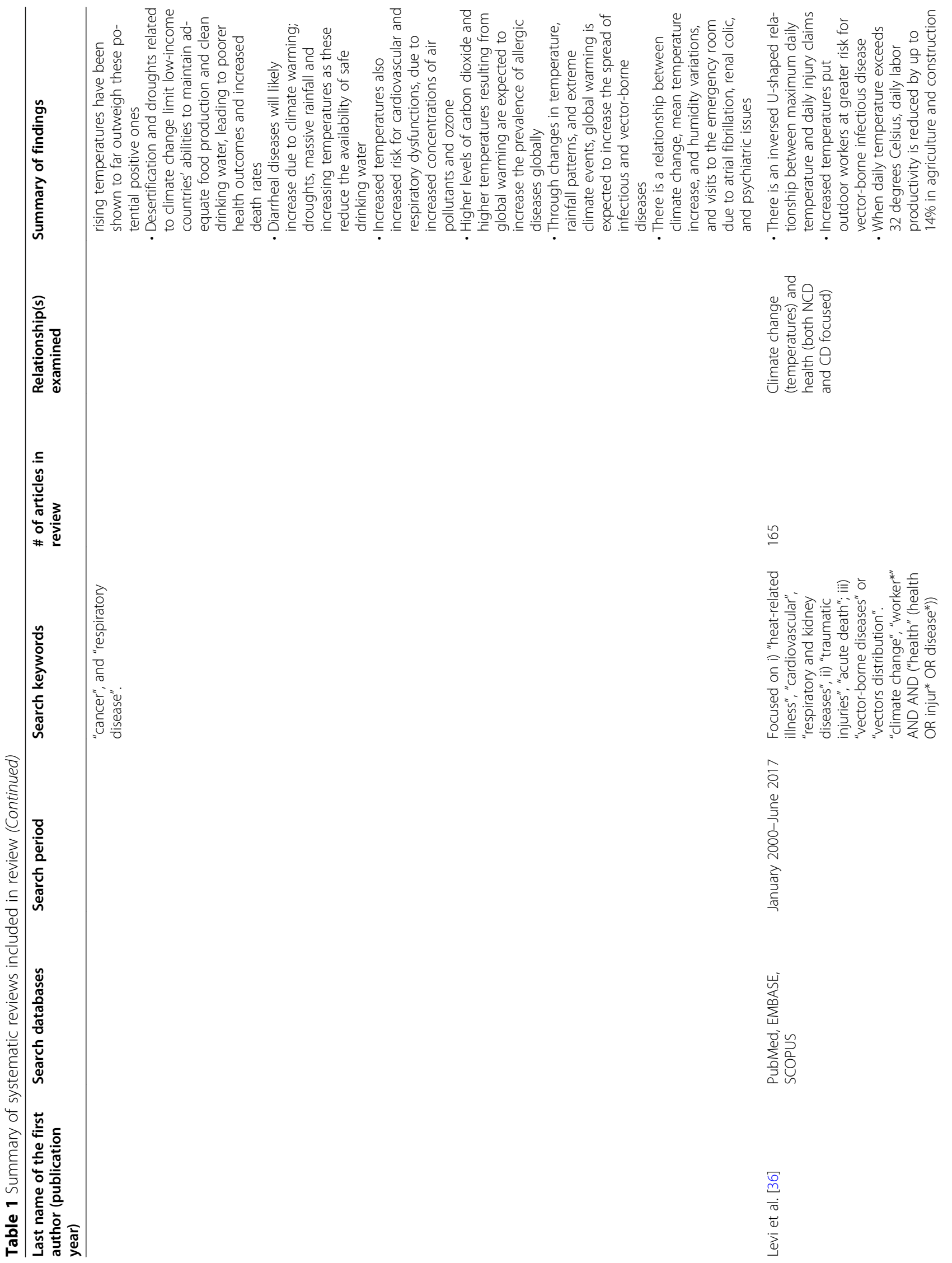




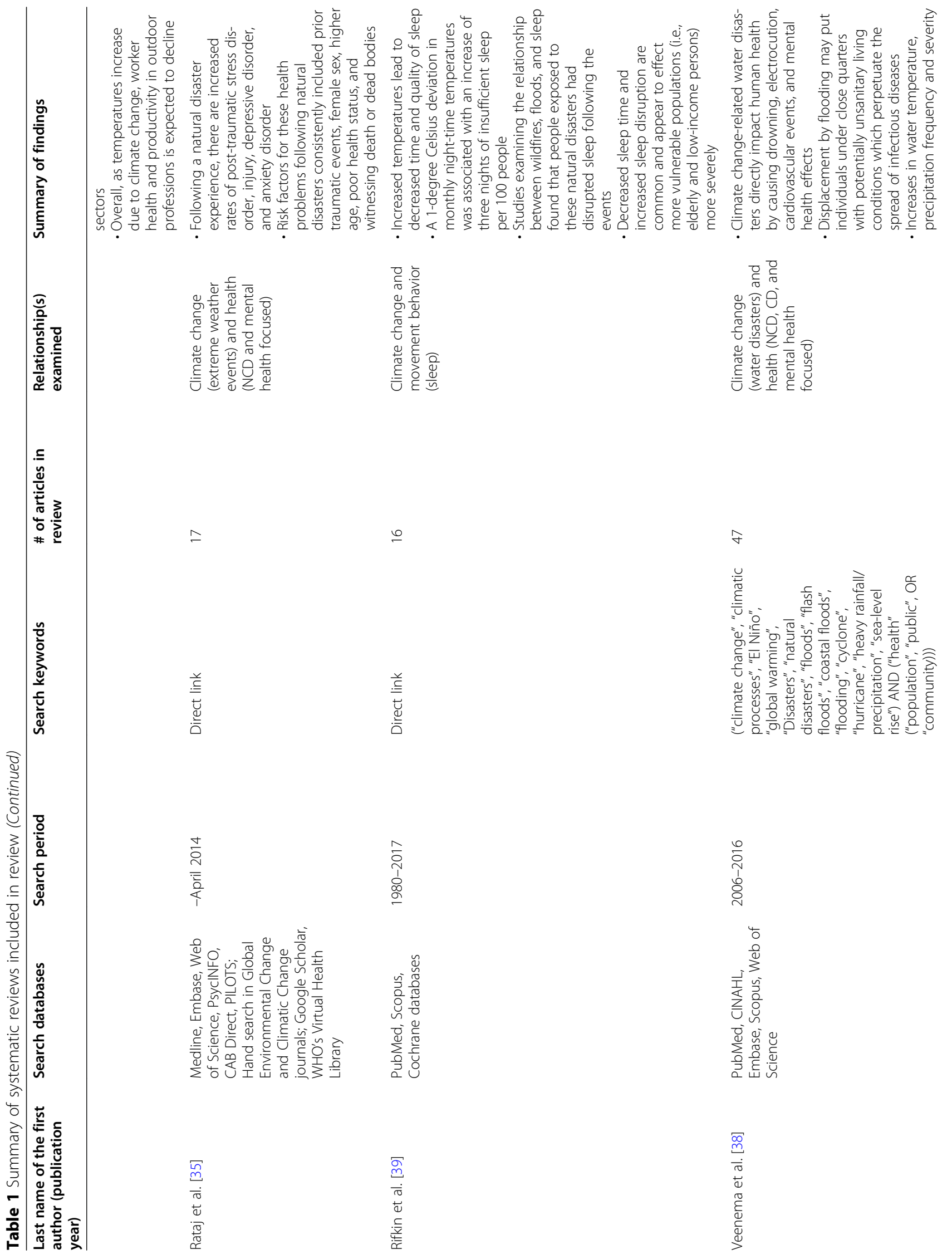




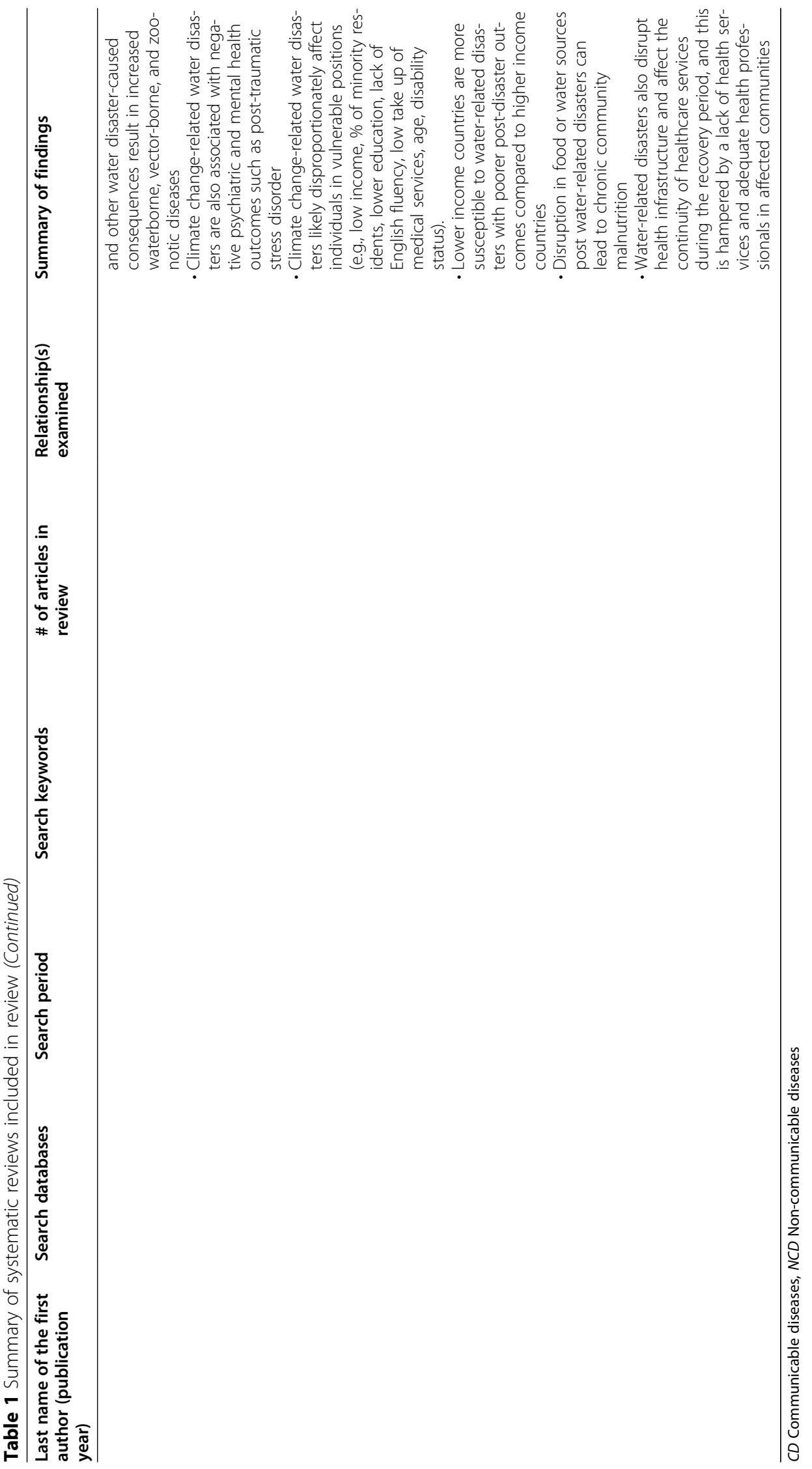


that increased temperatures lead to decreased sleep quality. Additionally, people who experienced natural disasters were more likely to experience disrupted sleep following the events. In another review [40], a bidirectional relationship between climate change and PA/ sport was identified. Varying indicators of climate change were associated with low PA with disproportionate impact on individuals with chronic diseases and older people. The review also suggested that PA contributes to intensifying or mitigating climate change through active/passive modes of commuting and subsequent reductions/increase in GHGs. It was also discussed that access to $\mathrm{PA} /$ sport infrastructure may be important factors for recovery in communities affected by natural disasters; however, at the same time, mega sporting events, the professional sport industry, and related air travels by athletes and spectators are major sources of GHGs.

No systematic reviews were focused on the associations between climate change and SB; however, one review on climate change and $\mathrm{PA}$ [40] included two studies which examined the unfavorable impact of climate change related indicators on sedentary time. Specifically, one study observed a high level of sedentary time among those who experienced Hurricane Ike, as a symptom of post-traumatic stress compared to nondisaster samples [42]. Another original study that was included in the review [40] showed higher levels of sedentary time in the areas of Beijing that exhibit highly concentrated air pollution [43].

\section{Climate change, 24-h movement behaviors, and health}

None of the identified reviews examined the relationship between all three variables of interest (i.e., climate change and 24-h movement behaviors and/or health) together. One paper [39] alluded to the emerging threats of climate change on sleep duration and interruption, and consequently, increased risk for NCDs given the strong evidence suggesting the association between shortened sleep duration and NCD-related burden. However, Rifkin and colleagues [39] highlighted that the evidence identifying clear links between climate change, sleep, and health remains an important gap requiring attention in future research. The importance of better elucidating the mechanisms between climate change and movement behaviors and/or health has also been highlighted in another review [40]. Specifically, it was noted that increasing incidence of vector-borne diseases such as Lyme disease or Malaria may negatively influence outdoor or occupational PA or active travel.

Based on this mini umbrella review, a conceptual framework outlining potential pathways between climate change, 24-h movement behaviors, and health is proposed (Fig. 2) to provide a greater understanding of these multifactorial, multi-directional, and complex relationships. Fig. 2 represents the results from each systematic review article included in this work. Briefly, there are multi-directional relationships between climate change and health, a potential uni-directional relationship between climate change and NCDs via sleep, and bi-directional relationships between climate change and PA. Evidence clarifying the relationship between climate change and SB appears to be largely lacking and warrants future work; however, the potential link is indicated based on previous literature [42-44]. Though the relationships between climate change, 24-h movement behaviors, and health cannot be clarified through this review, individual relationships between climate change and health $[35,36]$, climate change and 24-h movement behaviors $[39,40]$, and 24-h movement behaviors and health [9-11] were speculated. A clear mechanism linking the three variables of interest appears to be an important gap requiring further research. In addition, other human behaviors that occur on a day-to-day basis, for example, dietary habits, eco-friendly behavior, or consumer behavior, may also explain the links between climate change and health; therefore, future research may expand this line of inquiry beyond 24-h movement behaviors.

\section{Discussion}

Based on the evidence from eight systematic reviews published in the past decade, a multi-directional link between climate change and human health was observed. Specifically, uni-directional [35, 37, 39], bi-directional [33, 34, 38], and U-shaped associations [36] were observed between climate change and varying human health outcomes. Less is understood about the association between climate change and 24-h movement behaviors. Two reviews suggested the negative impact of climate change on sleep [39] and bi-directional relationships between climate change and PA/sport [40] with partial evidence on SB. No reviews examined the mechanisms by which climate change, 24-h movement behaviors, and health influence one another.

Of the research exploring the impact of climate change on human health, there appears to be a general consensus that climate change is expected to negatively impact various aspects of human health [35, 37-39]. It is also important to note that climate change will disproportionately generate greater risks for low- and middle-income countries (LMIC) [38, 45]. In LMICs, economic loses are largely uninsured (approximately 99\%), as such the economic impact of climate change is greater than it is in high-income countries, leading to poorer health outcomes for their citizens. This is because there is less resiliency spending and generally poorer health infrastructure; therefore, when climate change-related disasters happen, it is 


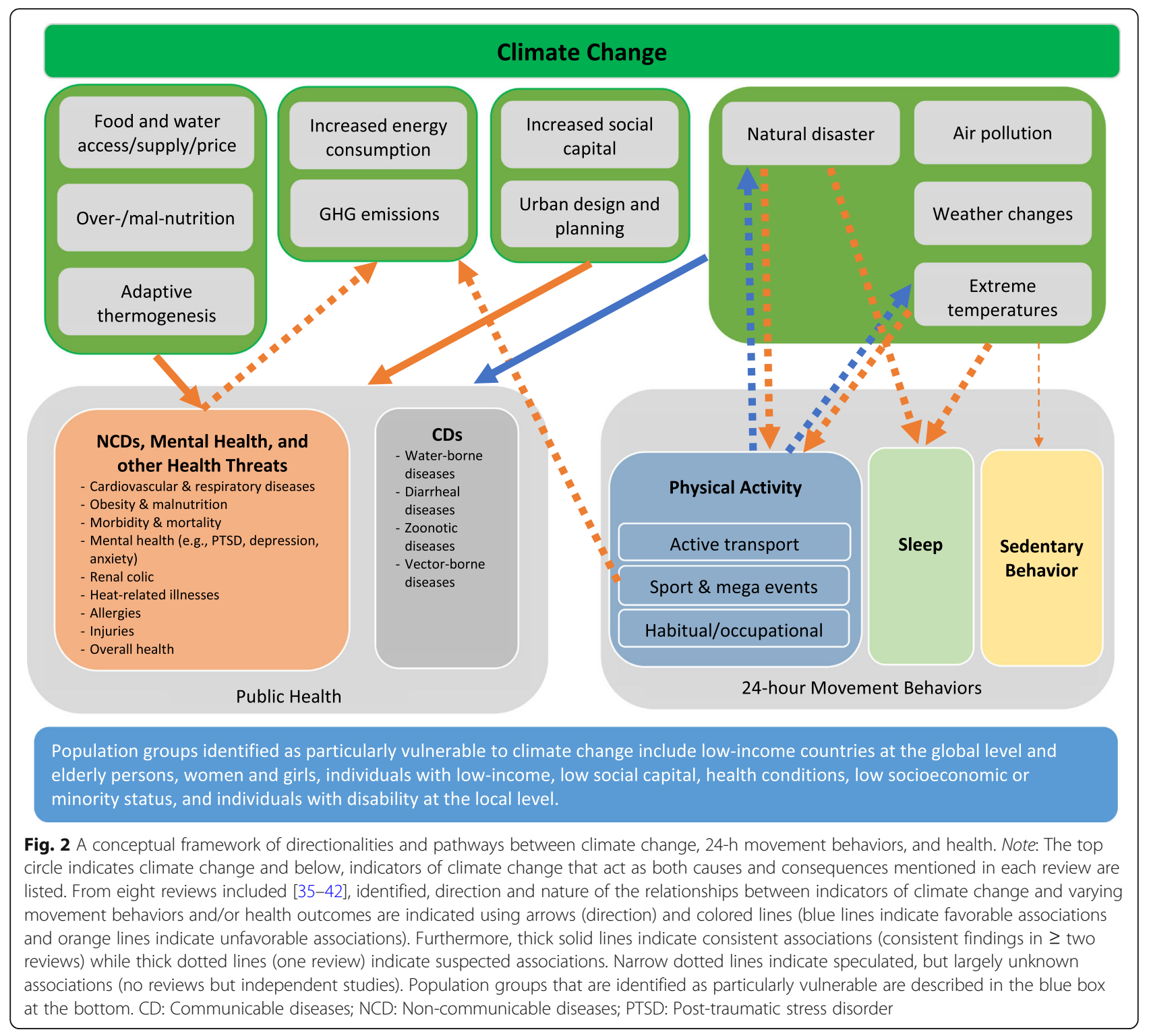

more difficult for LMICs to recover from and adapt to the changes [45]. It is also reported that at the local level, elderly and low-income individuals [38, 39], individuals with low social capital [33], women and girls [35], and individuals with health conditions [35], low socioeconomic or minority status, as well as individuals with disability [38] are more likely the be more vulnerable to climate change than their respective counterparts. Therefore, climate change mitigation and adaptation strategies should pay close attention to population countries/communities/ groups that are more vulnerable to climate change.

Limited, yet apparent associations between climate change and 24-h movement behaviors, specifically sleep [39] and PA/sport, [40] were observed. The relationship reported between climate change and sleep was unidirectional of which increased temperatures and natural disasters due to climate change diminishes and interrupts sleep, especially among low-income and elderly persons [39]. Bi-directional associations between climate change and PA/sport [40] indicated that climate change disproportionately impacts PA in the global population. At the same time, PA can mitigate or exacerbate climate change. Specifically, consistent, negative impacts of air pollution, extreme temperatures, and natural disasters on PA was reported. However, the impact of extreme temperatures on people's ability to engage in PA, particularly in outdoor activities, can vary by geographical location. For instance, people living in the north temperate zone (e.g., Canada) may not be affected at a same rate as those in the south temperate zone (e.g., Australia) [25, 40]. Such "place effects [46]" and their potential mediating role between climate change and health are being increasingly discussed in the literature $[46,47]$. 
While preliminary evidence suggests that seasonal variation may influence SB [48], no reviews were focusing on exploring $\mathrm{SB}$ in relation to climate change. Only two original studies included in the review on climate change and PA [40] reported a negative impact of climate change-related indicators on SB [42, 43]. Given the co-dependent relationship between $\mathrm{PA}$ and $\mathrm{SB}$, combined with the well-known health impacts of SB [49], it is important to clarify the potential bi-directional relationships between climate change and SB. In particular, screen time, the most common form of SB that is known to negatively impact health [50] is of great interest. It is projected that the Information Technology sector from powering internet servers and charging personal individual devices will consume as much a $20 \%$ of the world's electricity by 2030 [51]. In the era of climate change, supporting individuals to adjust their time-composition of 24-h movement behaviors so that they engage less in 'carbon-intensive' screen-based sedentary behaviors (e.g., streaming movies online), and instead engage in more emission-free SBs (e.g., board games, reading) or varying types of PA should be a priority [52]. Future studies should further explore this relationship in order to provide an understanding of whether this relationship exists, the directions of this relationship, and the possible pathways through which PA and SB interact with each other, and influence and are influenced by climate change.

This review suggests potential directions and pathways between climate change, 24-h movement behaviors, and health and provides a conceptual framework (Fig. 2) that could guide future research on the topic. Some limitations should be noted. This review only included systematic reviews in English and published between 2010 and 2020. In addition, only a limited number of keywords was used in literature searches; therefore, it is possible that reviews specific to one form of disease (e.g., vectorborne disease) or 24-h movement behavior (e.g., active transport, screen time) may have been missed; however, this is unlikely because we also conducted multiple searches on Google Scholar to cross-reference results and additional work was found via expert's suggestion. Finally, assessment of methodological quality/critical appraisal for each systematic review was not conducted given the broad scope and exploratory nature of the present review.

\section{Conclusions}

This mini umbrella review highlights the importance of better understanding the mechanisms between climate change, 24-h movement behaviors, and health to develop effective mitigation and adaptation strategies to climate change. The impact of climate change on human health could be intensified or buffered by $24-\mathrm{h}$ movement behaviors; however, this requires further investigations to be more conclusive. It is also noteworthy to mention that, in support of previous literature, the findings of this review build on the assertation that promoting healthy movement behaviors can address two major pressing issues of our era, climate change and human health. By considering knowledge pertaining to climate change and health and exploring factors that are linked with both climate change and health, such as 24-h movement behaviors, human health can be better protected through climate change mitigation and adaptation efforts. In making such efforts, it is important to consider countries/communities/population groups that are most vulnerable to climate change.

\section{Abbreviations \\ CD: Communicable diseases; LMIC: Low- and middle-income countries; NCD: Non-communicable diseases; PA: Physical activity; PRISMA: Preferred Reporting Items for Systematic Reviews and Meta-Analyses; SB: Sedentary behavior}

\section{Acknowledgements}

This work was completed as part of the undergraduate research internship course (KNPE/HLTH352) at Queen's University, Canada. In addition to this work, EL is currently leading a systematic review on climate change, 24-h movement behaviors, and health (PROSPERO \#CRD42020167386).

\section{Authors' contributions}

EL conceptualized and designed the review. EZ led literature searches with SH's support. EZ imported records, removed duplicates, conducted the screening of the records, and extracted the data. Literature search, data screening, and data extraction were verified by EL and SH. EZ wrote the first draft of the manuscript. EL contributed substantially to manuscript writing and revised the manuscript critically for important intellectual content. SH assisted with manuscript preparation for journal submission. All authors read and approved the final manuscript.

\section{Funding}

Not applicable.

Availability of data and materials

Not applicable.

\section{Declarations}

Ethics approval and consent to participation

Not applicable.

Consent for publication

Not applicable.

\section{Competing interests}

The authors declare that they have no competing financial interests.

Received: 20 November 2020 Accepted: 21 April 2021

Published online: 29 April 2021

References

1. Simpson MJ. Global climate change impacts in the United States. J Environ Qual. 2011;40(1):279. https://doi.org/10.2134/jeq2010.0010br.

2. Trombetta MJ. Environmental security and climate change: analysing the discourse. Camb Rev Int Aff. 2008;21(4):585-602. https://doi.org/10.1080/ 09557570802452920.

3. The Lancet Planetary Health. The world's biggest threats are environmental risks. Nat Clim Chang. 2018;8:7-10.

4. Barrett B, Charles JW, Temte JL. Climate change, human health, and epidemiological transition. Prev Med. 2015;70:69-75. https://doi.org/10.1016/ j.ypmed.2014.11.013. 
5. World Health Organization. Climate change and health [Internet]. [cited 2020 Jul 29]. Available from: https://www.who.int/news-room/fact-sheets/ detail/climate-change-and-health

6. Piao S, Ciais P, Huang Y, Shen Z, Peng S, Li J, et al. The impacts of climate change on water resources and agriculture in China. Nature. 2010;467(7311): 43-51. https://doi.org/10.1038/nature09364.

7. Alae-Carew C, Nicoleau S, Bird FA, Hawkins P, Tuomisto HL, Haines A, et al. The impact of environmental changes on the yield and nutritional quality of fruits, nuts and seeds: a systematic review. Environ Res Lett. 2020;15(2): 23002. https://doi.org/10.1088/1748-9326/ab5cc0.

8. Watts N, Adger WN, Ayeb-Karlsson S, Bai Y, Byass P, Campbell-Lendrum D, et al. The lancet countdown: tracking progress on health and climate change. Lancet. 2017;389(10074):1151-64 [cited 2019 Mar 15]; Available from: https://www.sciencedirect.com/science/article/pii/S0140673616321249.

9. Tremblay MS, Carson V, Chaput JP, Connor Gorber S, Dinh T, Duggan M, et al. Canadian 24-hour movement guidelines for children and youth: an integration of physical activity, sedentary behaviour, and sleep. Appl Physiol Nutr Metab. 2016;41(6):S311-27. https://doi.org/10.1139/apnm-2016-0151.

10. Tremblay MS, Chaput J-P, Adamo KB, Aubert S, Barnes JD, Choquette L, et al. Canadian 24-hour movement guidelines for the early years ( $0-4$ years): an integration of physical activity, sedentary behaviour, and sleep. BMC Public Health. 2017;17(Suppl 5):874. [cited 2017 Dec 12]. https://doi.org/1 0.1186/s12889-017-4859-6.

11. Bull FC, Al-Ansari SS, Biddle S, Borodulin K, Buman MP, Cardon G, et al. World Health Organization 2020 guidelines on physical activity and sedentary behaviour [Internet]. Br J Sports Med. 2020;54:1451-62. Available from: http://bjsm.bmj.com. BMJ Publishing Group; [cited 2021 Mar 18]

12. Tremblay MS, Esliger DW, Tremblay A, Colley R. Incidental movement, lifestyle-embedded activity and sleep: new frontiers in physical activity assessment. Appl Physiol Nutr Metab. 2007;32(Suppl 2):S208-17. https://doi. org/10.1139/H07-130.

13. Fox KR, Hillsdon M. Physical activity and obesity. Obes Rev. 2007:8(Suppl. 1): 115-21. https://doi.org/10.1111/j.1467-789X.2007.00329.X.

14. Koplan JP, Powell KE. Physicians and the Olympics. JAMA. 1984;252(4):529_ 30. https://doi.org/10.1001/jama.1984.03350040059026.

15. Kirchengast S. Physical inactivity from the viewpoint of evolutionary medicine. Sports. 2014;2(2):34-50. https://doi.org/10.3390/sports2020034.

16. Akpan UF, Akpan GE. The contribution of energy consumption to climate change: a feasible policy direction. Int J Energy Econ Policy. 2012;2(1):21.

17. Mekary RA, Willett WC, Hu FB, Ding EL. Isotemporal substitution paradigm for physical activity epidemiology and weight change. Am J Epidemiol. 2009;170(4):519-27 [cited 2019 Sep 13] Available from: https://academic. oup.com/aje/article-abstract/170/4/519/90085

18. Huang WY, Wong SHS, He G, Salmon J. Isotemporal substitution analysis for sedentary behavior and body mass index. Med Sci Sports Exerc. 2016;48(11): 2135-41 [cited 2019 Sep 13] Available from: http://insights.ovid.com/ crossref?an=00005768-201611000-00008

19. Boyle T, Vallance JK, Buman MP, Lynch BM. Reallocating time to sleep, sedentary time, or physical activity: Associations with waist circumference and body mass index in breast cancer survivors. Cancer Epidemiol Biomark Prev. 2017;26(2):254-60 [cited 2019 Sep 13] Available from: http://www.ncbi. nlm.nih.gov/pubmed/27780817.

20. Colley RC, Michaud I, Garriguet D. Reallocating time between sleep, sedentary and active behaviours: associations with obesity and health in Canadian adults. Heal Rep. 2018;29(4):1-13 [cited 2018 Apr 24]. Available from: http://www.statcan.gc.ca/pub/82-003-x/2018004/article/54951-eng.pdf.

21. Fanning J, Porter G, Awick EA, Ehlers DK, Roberts SA, Cooke G, et al. Replacing sedentary time with sleep, light, or moderate-to-vigorous physical activity: effects on self-regulation and executive functioning. J Behav Med. 2017;40(2): 332-42. https://doi.org/10.1007/s10865-016-9788-9 [cited 2019 Sep 13].

22. Carson V, Tremblay MS, Chaput J-P, Chastin SFM. Associations between sleep duration, sedentary time, physical activity, and health indicators among Canadian children and youth using compositional analyses ${ }^{1}$. Appl Physiol Nutr Metab. 2016;41(6 (Suppl. 3)):S294-302. https://doi.org/10.1139/a pnm-2016-0026.

23. Vallance JK, Buman MP, Lynch BM, Boyle T. Reallocating time to sleep, sedentary, and active behaviours in non-Hodgkin lymphoma survivors: associations with patient-reported outcomes. Ann Hematol. 2017;96(5):74955. https://doi.org/10.1007/s00277-017-2942-9 [cited 2019 Sep 13].

24. Stamatakis E, Rogers K, Ding D, Berrigan D, Chau J, Hamer M, et al. All-cause mortality effects of replacing sedentary time with physical activity and sleeping using an isotemporal substitution model: a prospective study of 201,129 mid-aged and older adults. Int J Behav Nutr Phys Act. 2015;12(1): 121 [cited 2019 Sep 13] Available from: http://www.ijbnpa.org/ content/12/1/121.

25. IPPC W. IPCC fifth assessment report [internet]. Climate change 2014: impacts, adaptation, and vulnerability; 2013. p. 1-153. Available from: pa pers3://publication/uuid/COE2E94D-F6E0-4227-962E-BE16FAE53BCA.

26. Elfar JC. Introduction to mini-review. Geriatr Orthop Surg Rehabil. 2014;5(2): 36. Available from: https://www.ncbi.nlm.nih.gov/pmc/articles/PMC4212371. [cited 2021 Jan 5]

27. Aromataris E, Fernandez R, Godfrey C, Holly C, Khalil H, Tungpunkom P. Chapter 10: umbrella reviews. In: JBI manual for evidence synthesis: JBI; 2020.

28. Moher D, Shamseer L, Clarke M, Ghersi D, Liberati A, Petticrew M, et al. Preferred reporting items for systematic review and meta-analysis protocols (PRISMA-P) 2015 statement. Rev Esp Nutr Humana Diet. 2016:20(2):148-60.

29. Climate change / United Nations [Internet]. Available from: https://www.un. org/en/sections/issues-depth/climate-change. [cited 2021 Jan 5]

30. Lee E-Y, Hakimi S, Janssen I. A systematic review on climate change, 24hour movement behaviours, and health [Internet]. [cited 2021 Jan 5]. Available from: https://www.crd.york.ac.uk/prospero/display_record. php?RecordID=167386.

31. Pedišić Ž, Dumuid D, Olds TS. Integrating sleep, sedentary behaviour, and physical activity research in the emerging field of time-use epidemiology: definitions, concepts, statistical methods, theoretical framework, and future directions. Kinesiology. 2017:49(2):252-69.

32. World Health Organization. What is the WHO definition of health? [Internet] [cited 2020 Jul 29]. Available from: https://www.who.int/about/who-we-are/ frequently-asked-questions.

33. Cheng JJ, Berry P. Health co-benefits and risks of public health adaptation strategies to climate change: a review of current literature. Int J Public Health. 2013;58(2):305-11. https://doi.org/10.1007/s00038-012-0422-5.

34. An R, Ji M, Zhang S. Global warming and obesity: a systematic review. Obes Rev. 2018;19(2):150-63. https://doi.org/10.1111/obr.12624.

35. Rataj E, Kunzweiler K, Garthus-Niegel S. Extreme weather events in developing countries and related injuries and mental health disorders - a systematic review. BMC Public Health. 2016;16(1):1020. https://doi.org/10.11 86/s12889-016-3692-7

36. Levi M, Kjellstrom T, Baldasseroni A. Impact of climate change on occupational health and productivity: a systematic literature review focusing on workplace heat. Med Lav. 2018;109(3):163-79.

37. Franchini M, Mannucci PM. Impact on human health of climate changes. Eur J Intern Med. 2015;26(1):1-5. https://doi.org/10.1016/j.ejim.2014.12.008.

38. Veenema TG, Thornton CP, Lavin RP, Bender AK, Seal S, Corley A. Climate change-related water disasters' impact on population health. J Nurs Scholarsh. 2017;49(6):625-34. https://doi.org/10.1111/jnu.12328 [cited 2020 Sep 22].

39. Rifkin DI, Long MW, Perry MJ. Climate change and sleep: a systematic review of the literature and conceptual framework. Sleep Med Rev. 2018;42: 3-9. https://doi.org/10.1016/j.smrv.2018.07.007.

40. Bernard P, Chevance G, Kingsbury C, Baillot A, Romain AJ, Molinier V, et al. Climate change, physical activity and sport: a systematic review. Sports Med 2021;51(5):1041-59. https://doi.org/10.1007/s40279-021-01439-4.

41. Bloetscher F, Polsky C, Bolter K, Mitsova D, Garces KP, King R, et al. Assessing potential impacts of sea level rise on public health and vulnerable populations in Southeast Florida and providing a framework to improve outcomes. Sustain. 2016;8(4):1-18.

42. Lai BS, La Greca AM, Llabre MM. Children's sedentary activity after hurricane exposure. Psychol Trauma Theory Res Pract Policy. 2014;6(3):280-9 [cited 2020 Jul 29] Available from: /record/2013-27841-001.

43. Yu H, Ngjun CJ, Gordon SP, An R, Yu M, et al. Impact of air pollution on sedentary behavior: a cohort study of freshmen at a university in Beijing, China. Int J Environ Res Public Health. 2018;15(12):2811 [cited 2020 Jul 29] Available from: http://www.mdpi.com/1660-4601/15/12/2811

44. An R, Zhang S, Ji M, Guan C. Impact of ambient air pollution on physical activity among adults: a systematic review and meta-analysis. Perspect Public Health. 2018;138(2):111-21. https://doi.org/10.1177/175791391772 6567

45. Watts N, Amann M, Ayeb-Karlsson S, Belesova K, Bouley T, Boykoff M, et al. The lancet countdown on health and climate change: from 25 years of inaction to a global transformation for public health. Lancet. 2018; 391(10120):581-630. https://doi.org/10.1016/S0140-6736(17)32464-9. 
46. Macintyre S, Ellaway A, Cummins S. Place effects on health: how can we conceptualise, operationalise and measure them? Soc Sci Med. 2002;55(1): 125-39. https://doi.org/10.1016/S0277-9536(01)00214-3.

47. Hess JJ, Malilay JN, Parkinson AJ. Climate change: the importance of place. Am J Prev Med. 2008;35(5):468-78. https://doi.org/10.1016/j.amepre.2008.08. 024.

48. Atkin AJ, Sharp SJ, Harrison F, Brage S, Van Sluijs EMF. Seasonal variation in children's physical activity and sedentary time. Med Sci Sports Exerc. 2016; 48(3):449-56. https://doi.org/10.1249/MSS.0000000000000786.

49. De Rezende LFM, Lopes MR, Rey-Ló́ez JP, Matsudo VKR, Luiz ODC. Sedentary behavior and health outcomes: an overview of systematic reviews. PLoS One. 2014;21:9(8).

50. Mullane SL, Pereira MA, Buman MP. Sedentary behaviour at the community level: correlates, theories, and interventions. In: Sedentary behaviour epidemiology. Springer; 2018. p. 509-43.

51. Andrae A, Edler T. On global electricity usage of communication technology: trends to 2030. Challenges. 2015;6(1):117-57. https://doi.org/1 0.3390/challe6010117.

52. Lee E-Y, Hakimi S, Zisis E. Active living and population health in the era of climate crisis [internet]. Centre for Active Living; 2020. Available from: https:/www.centre4activeliving.ca/news/2020/03/climate-change.

Ready to submit your research? Choose BMC and benefit from:

- fast, convenient online submission

- thorough peer review by experienced researchers in your field

- rapid publication on acceptance

- support for research data, including large and complex data types

- gold Open Access which fosters wider collaboration and increased citations

- maximum visibility for your research: over $100 \mathrm{M}$ website views per year

At $\mathrm{BMC}$, research is always in progress.

Learn more biomedcentral.com/submissions 